\title{
Characterize the Demand and Energy \\ Characteristics of Direct Current Fast Chargers
}

Idaho National Laboratory

June 2015

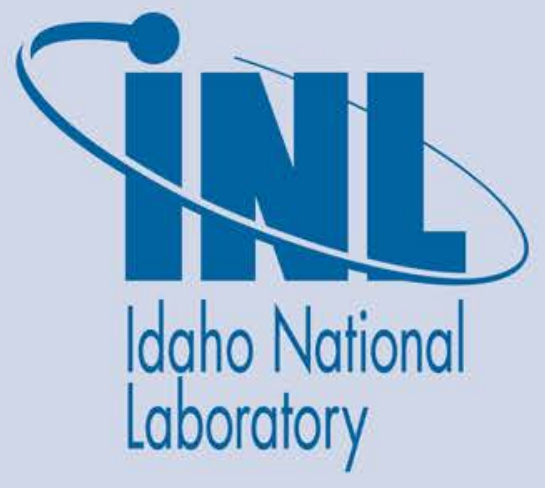

The INL is a U.S. Department of Energy National Laboratory operated by Battelle Energy Alliance 
INL/EXT-15-36318

\title{
Characterize the Demand and Energy Characteristics of Direct Current Fast Chargers
}

Idaho National Laboratory

June 2015

\section{Idaho National Laboratory \\ Idaho Falls, Idaho 83415}

http://www.inl.gov

\author{
Prepared for the \\ U.S. Department of Energy \\ Assistant Secretary for __, OR Office of \\ Under DOE Idaho Operations Office \\ Contract DE-AC07-05ID14517
}




\section{Characterize the Demand and Energy Characteristics of Direct Current Fast Chargers}

June 2015

\section{Key Conclusions}

- The introduction of usage fees had a significant effect on the utilization of direct current fast chargers (DCFC), reducing average utilization from 281.6 charge events per DCFC in the second quarter of 2013 to 100.1 charge events per DCFC in the fourth quarter of 2013.

- $\quad$ The DCFC peak demand and peak utilization occurred quite consistently among all regions of The EV Project between 4 and 7 p.m. each weekday.

- Half of all DCFC connect events were 20 minutes or less in duration. An average of $8.2 \mathrm{kWh}$ of energy was consumed during these events, with $80 \%$ of all connect events being less than 30 minutes.

- While the maximum power accepted by the Leaf battery management system (BMS) when fast charging is $50 \mathrm{~kW}$, the average actual Leaf BMS acceptance was approximately half that.

\section{Introduction}

The electric vehicle supply equipment (EVSE) deployed by The EV Project included both alternating current (AC) Level 2 EVSE and DCFC units. Over 100 of the Blink dual-port DCFCs were deployed by The EV Project. These DCFCs were all publicly accessible, located in workplaces, near traffic hubs, retail centers, parking lots, restaurants, and similar locations.

The Blink DCFC dual-port design sequences the charge from one port to the other, delivering power to only one of two vehicles connected at a time. The actual power delivered through a port is determined by the PEV's onboard BMS. The Blink DCFC is capable of charging at power up to $60 \mathrm{~kW}$. For The EV Project, the Nissan Leaf was the only participating PEV capable of accepting a DC charge. The Nissan Leaf BMS allows acceptance of up to $50 \mathrm{~kW}$ DC power. At this rate, the DCFC is capable of recharging a Leaf battery from a $30 \%$ state of charge to an $80 \%$ state of charge in about 25 minutes.

The power required by a DCFC to recharge a plug-in electric vehicle (PEV) can be a significant additional electrical load for the charging site host and contributes to overall power demand on the electric grid.

\section{Background}

A question frequently asked relating to the adoption of PEVs is "What is the impact of PEV charging on the electrical grid?" This question can be directed at the big picture of total utility system load or on the impact to the local charging site host.

DCFC charging impacts several areas of interest for charging site hosts and electric utilities. An initial look at DCFC charging was reported in What Are the Early Experiences in Using Direct Current Fast Chargers? ${ }^{1}$. Many electric utilities impose fees for power demand as part of their commercial rate structure. The impact of these demand charges was reported in the paper titled, What is the Impact of Utility Demand Charges on a Direct Current Fast Charger Host? ${ }^{2}$ The costs associated with DCFC installation were addressed in What were the Cost Drivers for the Direct Current Fast Charging Installations? ${ }^{3}$ Use patterns for DCFC was explored in the paper titled, What Were the Use Patterns Observed at the Highly Utilized Direct Current Fast Charge Sites? ${ }^{4}$

The focus of this paper is to identify the impact of DCFC charging on the total system load. It will also identify the characteristics of the aggregated group of DCFCs and a single typical DCFC and its charge profile or load duration curve.

\section{Data Analyzed}

The EV Project published reports on a quarterly basis on specific aggregated data points. Electric utilities within the boundaries of The EV Project specifically requested information related to the demand and energy requirements for charging PEVs. These reports are available at avt.inl.gov/evproject.shtml. Information from these quarterly reports was analyzed for this paper.

The EV Project collected charge data from the deployed Blink DCFC and these data were also analyzed herein. Eight months of charge data (i.e., January through August 2013) were selected to perform global analyses of data from The EV Project. Because full enrollment of PEV drivers was completed in January 2013, PEV drivers were well aware of the location of these DCFC.

The first quarter and fourth quarter of 2013's charge data for San Diego were used for specific analysis. The fee structure for DCFC access was implemented in the third quarter of 2013 and its effect on utilization is examined. 


\section{Direct Current Fast Charger Deployment}

By the end of December 2013, The EV Project had installed 107 Blink DCFC in seven states (Table 1).

Table 1. DCFC installed by The EV Project.

\begin{tabular}{lc}
\multicolumn{1}{c}{ Region } & Number of DCFC \\
\hline Arizona & 18 \\
California - Los Angeles & 6 \\
California - San Diego & 4 \\
California - San Francisco & 28 \\
Georgia & 2 \\
New Jersey (Philadelphia) & 1 \\
Oregon & 16 \\
Tennessee & 16 \\
Washington State & 16 \\
\hline
\end{tabular}

Figure 1 shows the number of charge events and deployed DCFCs by quarter.

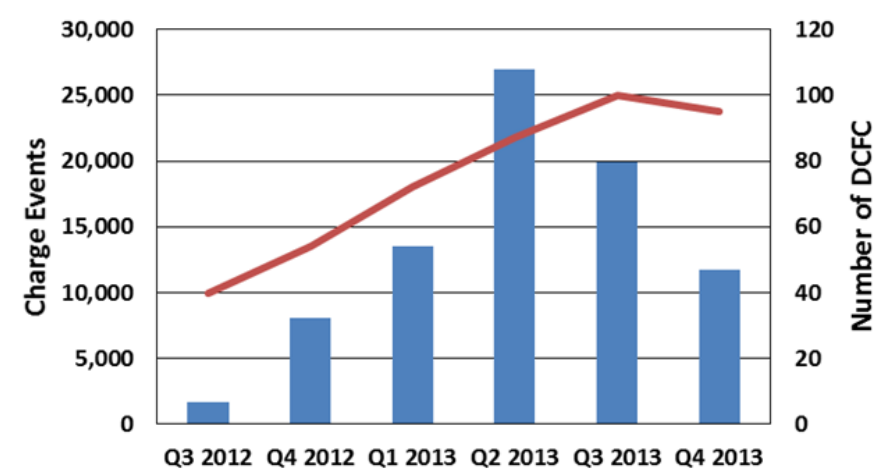

DCFC Charge Events Number of DCFC

Figure 1. DCFC deployed and charge events in The EV Project by quarter.

The report for the fourth quarter of 2013 included data from 95 of the deployed DCFCs. The 11,704 charging events represented $2 \%$ of the total charging events for the quarter within The EV Project, including residential, non-residential AC Level 2 EVSE, and DCFC. DCFC were available to all PEVs equipped with CHAdeMO fast charge inlets and 82\% of the charge events were by PEVs not enrolled in The EV Project. Because the Leaf was the predominant PEV capable of accepting fast charging at that time, this $82 \%$ was most likely also done by Leafs.

\section{Utilization}

Figure 2 shows the average number of charge events per day per DCFC unit per EV Project region.

During the second quarter of 2013, the overall average utilization was 3.1 charge events per DCFC per day or 281.6 charge events per DCFC for the quarter. This compares to 15.7 charge events per AC Level 2 EVSE deployed in The EV Project during that quarter. On average, utilization of DCFC was 18 times higher than AC Level 2 EVSE on a per unit basis. This result should be viewed in the context of the significantly higher number of AC Level 2 EVSE available in the region.

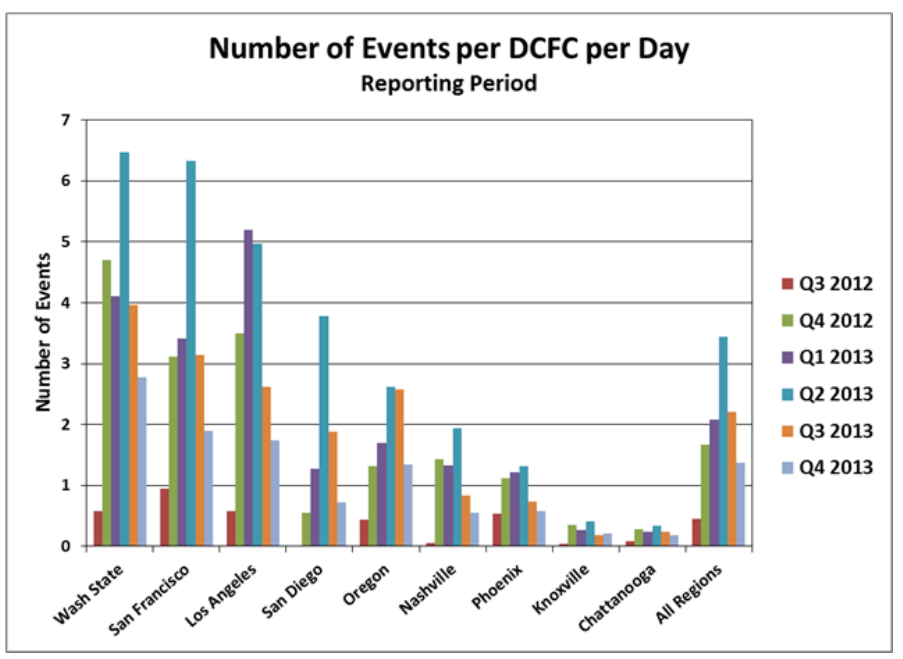

Figure 1. Average number of charge events per DCFC per day by quarter.

There is a noticeable drop in the average number of charge events per DCFC per day from the second quarter to the third and fourth quarters in both Figures 1 and 2. As noted above, fees for use were integrated into access control during the third quarter. Comparing the second and fourth quarter of 2013 for the San Francisco region provides the information in Table 2.

Table 2. San Francisco DCFC summary for the second and fourth quarters of 2013.

\begin{tabular}{lcc} 
& Quarter 1 & Quarter 4 \\
\multicolumn{1}{c}{ Attribute } & 2013 & 2013 \\
\hline DCFCs Installed & 21 & 27 \\
Total Connect Events & 11,947 & 4,612 \\
Average Energy Consumed (kWh) & 8.60 & 9.49 \\
Average Number Charge & 6.71 & 1.86 \\
Events/DCFC/Day & & \\
\hline
\end{tabular}

Although an additional DCFC was installed in the region by the fourth quarter of 2013, the total connect events and number of charge events per DCFC per day declined.

At the same time, utilization of publicly accessible AC Level 2 was increasing. In the fourth quarter of 2013, the overall average utilization for DCFC was 1.1 charge events per DCFC per day or 100.1 charge events per DCFC during the quarter. This compares to 22.6 charge events per AC Level 2 EVSE deployed in The EV Project during that same quarter. On average, utilization of DCFC was 4.4 times higher than AC Level 2 EVSE on a per unit basis. 
The quarterly reports show that the total number of charging events dropped from 26,911 in the second quarter to 11,704 in the fourth quarter (i.e., a $56 \%$ reduction). A portion of this reduction results from the unreliability of the Blink AC Level 2 EVSE.

The University of California at Davis conducted a survey of San Diego participants as part of The EV Project.

Regarding access fees, the University of California at Davis reports, "Many PEV drivers tell us that paid away-fromhome charging is now an emergency back-up, not the perquisite is was when it was free... On the other hand, some participants believed the shift away from free public charging represented a necessary step and were comfortable paying for public charging."

The relative contribution of plug-in events by DCFC in each study region of The EV Project between January and August 2013 is shown in Figure A-1 of Appendix A. The number of charge events in all regions appears to have been affected by access fees. As seen in Figure A-1, the overall usage curves are highly influenced by significant usage in San Francisco.

While the quantity of charge events decreased, the overall usage profiles remained quite consistent.

\section{Demand Effects}

Charging demand is defined for this paper as the total amount of power being drawn from the electric grid by a group of DCFC in a geographical area. This is calculated by aggregating charge data generated from all Blink DCFCs' onboard meters in the area of interest over the timeframe desired. In Figure 3, demand for each day of the quarter is overlaid on the time of day; therefore, the upper blue line indicates maximum demand over the quarter, the red line shows minimum demand, and the black line shows median demand over the quarter. The inner quartiles are shown as gray-shaded areas. The data for weekdays and weekends are graphed separately. The following analysis uses the weekday median values for electrical demand.

Figure 3 shows the aggregated charging demand for all EV Project DCFC in the second quarter of 2013. The irregular shapes of all curves reflect the large impact of each DCFC charge.

In Figure 3, the median value and inner quartile regions are closely grouped, indicating close agreement between regions for these times of the day. A peak at approximately $0.20 \mathrm{MW}$ in median demand occurs between 4 and 7 p.m. daily.

Although the Leaf BMS allows a maximum of 50-kW power, not all plug-in events result in a charge at the maximum power level. Figure A-2 in Appendix A shows the energy delivered per time connected for all vehicles from January through August 2013. Nearly 7,500 of the 57,470 plug-in events resulted in less than 1-kWh energy charged, although connect times for these 7,500 events ranged up to 49 minutes. This abnormal condition could have been the result of vehicle charging limitations (e.g., a

high-temperature battery) or DCFC issues.

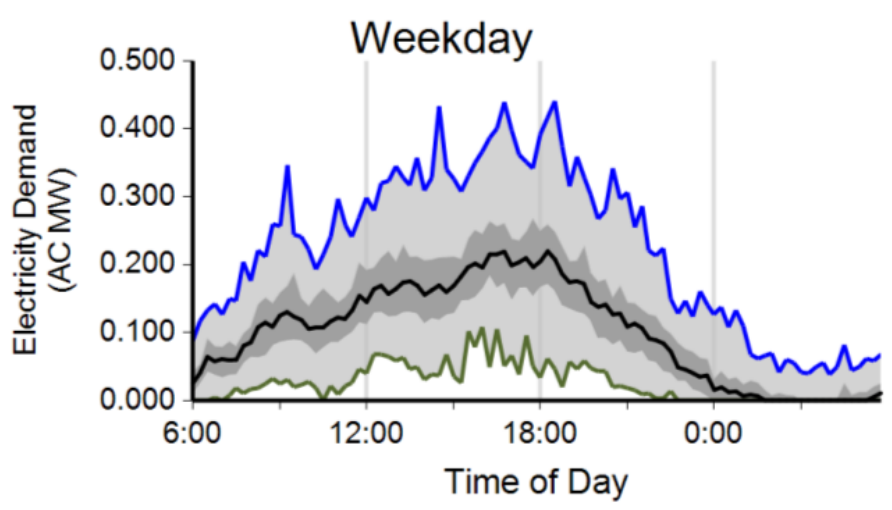

Figure 3. Aggregated DCFC charging demand for all regions of The EV Project during the second quarter of 2013.

\section{Connectivity}

\section{Charging Behavior}

Charging availability is defined as the percent of EVSE that have a PEV connected in a geographical area. This is calculated by aggregating the data generated from all of the Blink's onboard meters in the group of EVSEs being evaluated in the geographic area of interest over the timeframe desired. In these graphics, availability for each day of the quarter is overlaid on the time of day; therefore, the upper blue line indicates the maximum percent of EVSE with vehicles connected over the quarter, the red line shows the minimum availability, and the black line shows the median percentage of EVSE with vehicles connected over the quarter. The inner quartiles are shown as gray-shaded areas. The data for weekdays and weekends are graphed separately. The following analysis uses the weekday median values for charging availability.

Figure 4 shows the weekday aggregated DCFC charging availability over all EV Project regions in the second quarter of 2013. The shape of Figure 4 closely matches the shape of the corresponding charging demand of Figure 3. Users of publicly accessible EVSE expect the charge to commence immediately upon connecting a PEV to the EVSE. Thus, peak times of connectivity will coincide with the peaks identified for energy demand.

The median value and inner quartile regions are closely grouped, indicating close agreement between all DCFC. During this quarter, each region containing a significant number of DCFC experienced the peak in PEV connectivity 
of approximately $11 \%$ of the installed DCFC at $4: 30$ and the bulk of connectivity between 4 and 7 p.m.

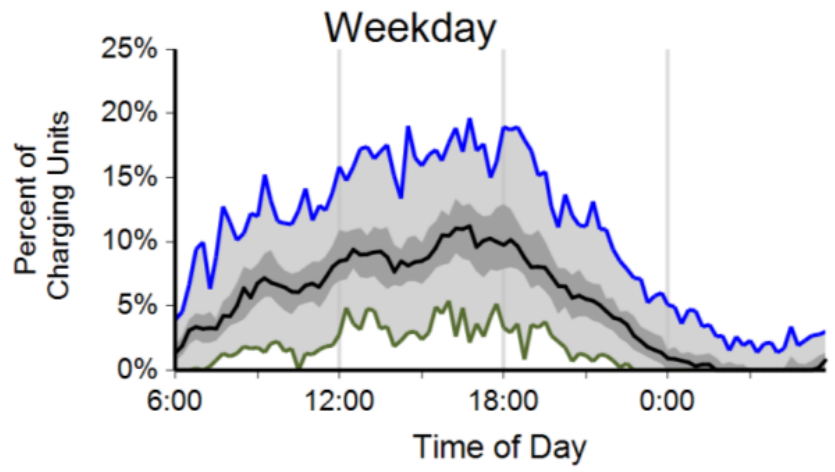

Figure 4. Charging availability for DCFC for all regions of The EV Project during the second quarter of 2013.

Figure 5 shows the percent of EVSE connected versus time of day for the first 8 months of 2013. peak connectivity occurs at 7 p.m. with $8.2 \%$ of all EVSE connected.

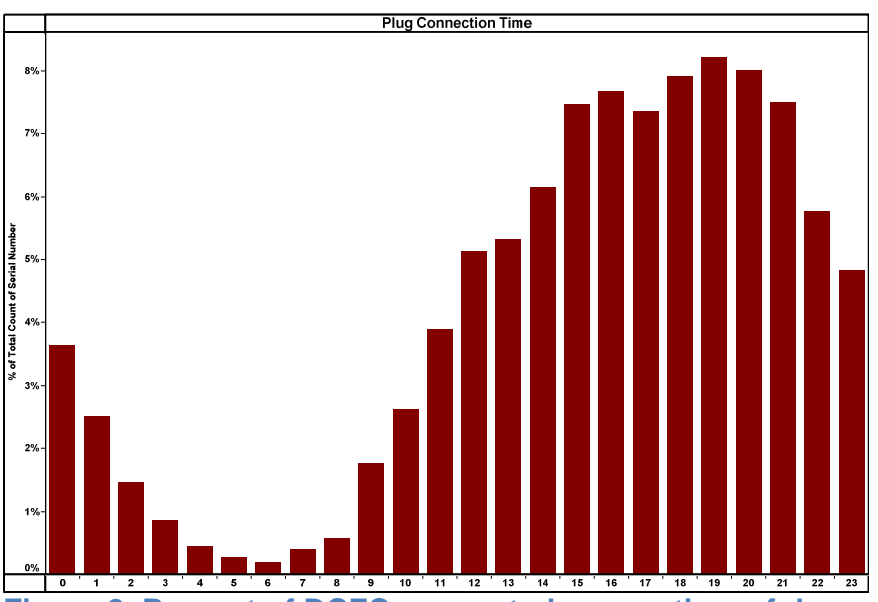

Figure 2. Percent of DCFC connected versus time of day.

The EV Project's quarterly reports may differ from the aggregated total due to data reporting requirements. Nevertheless, both show the general shape of connectivity, with minimum connectivity at approximately 6 a.m. and peak connectivity between 4 and 8 p.m.

Figure 6 shows the distribution of connect times once a $\mathrm{PEV}$ is connected to the DCFC during the first 8 months of 2013. Somewhat surprisingly, over $6,400(11 \%)$ events were less than 1-minute duration. This is likely due to PEV drivers testing their connectivity to the DCFC, because 1 minute is the maximum connect time allowed before charging fees accrue.

Using these Blink data for the first 8 months of 2013, half of all connect events were of 20 minutes or less duration. An average of $8.2 \mathrm{kWh}$ of energy was consumed during these events, with $80 \%$ of all events being less than 30 minutes.

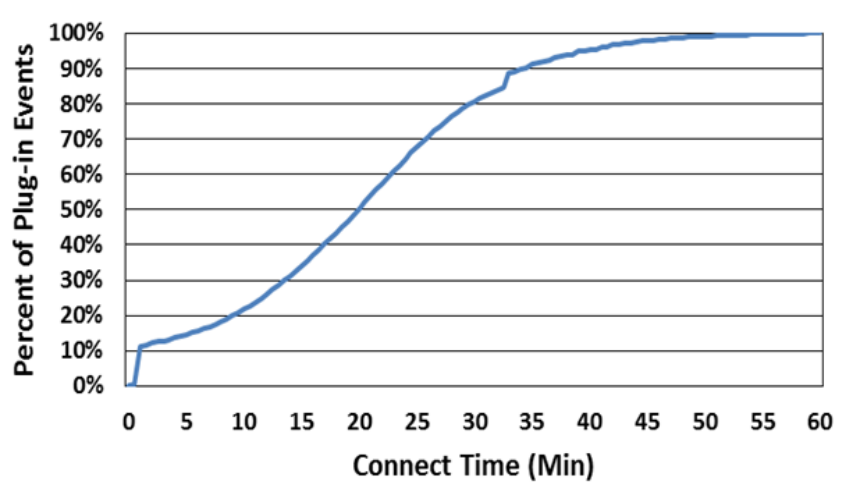

Figure 6. Cumulative distribution of connect times for all regions.

\section{Energy Consumed}

Figure 7 shows the total cumulative energy consumed versus time of day for the first 8 months of 2013. Because the energy is typically dispensed immediately upon connectivity, the shape is similar to that of Figure 5.

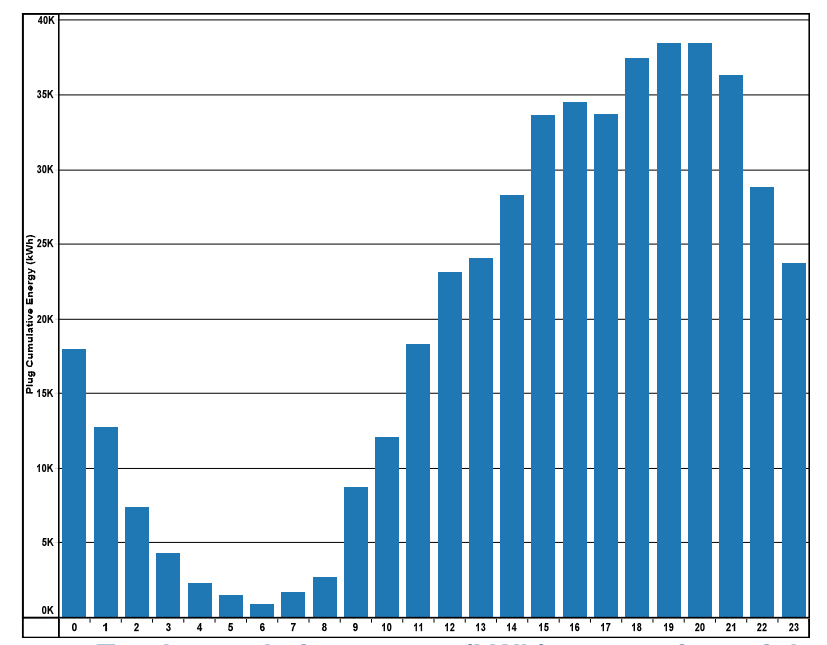

Figure 7. Total cumulative energy (kWh) versus time of day.

Figure 8 shows distribution of energy consumed per charge event, with $19 \%$ of all charge events resulting in 7.5 to $10 \mathrm{kWh}$ consumed.

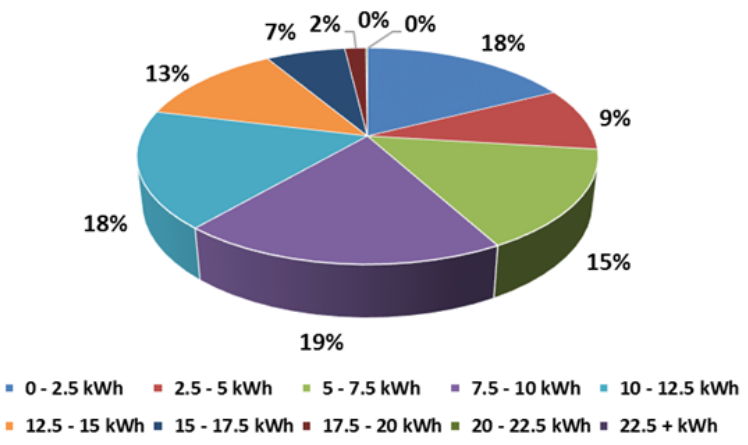

Figure 8. DCFC energy consumed. 
The fourth quarter report identifies that $75 \%$ of all energy consumed for DCFC charging events occurred during the weekdays. The average energy consumed per weekday charging event was $9.2 \mathrm{~kW}$.

\section{Direct Current Fast Charger Load Analysis}

The DCFC delivers power at the rate the PEV's onboard BMS accepts. Some of the vehicle factors that determine this maximum rate include battery conditions such as state of charge, temperature, and battery condition. The Leaf was the only PEV in The EV Project capable of charging at a DCFC and its highest maximum charge power was limited by the BMS to $50 \mathrm{~kW}$.

The 57,467 charge events in the first 8 months of 2013 provide the distribution shown in Figure 6 above and also provide an opportunity to estimate the maximum power demand per time of connectivity shown in Figure 9.

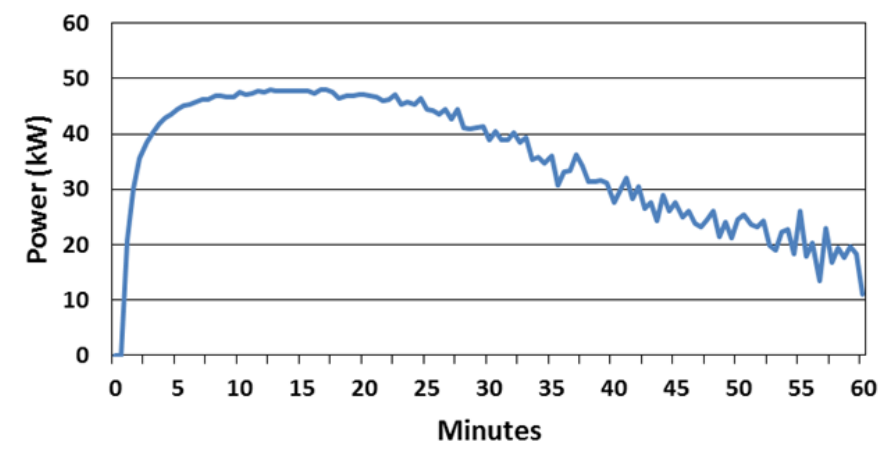

Figure 9. DCFC charge power versus time.

Because the number of PEVs connected declines significantly beyond 30 minutes, the curve is more influenced by individual PEV charging at that point. However, the slope of the curve is consistent. This could be used as a typical load duration curve for a Blink DCFC while charging a Leaf.

The Leaf BMS would typically terminate the charge at approximately an $80 \%$ battery state of charge. Reference 5 reports the average battery state of charge was $35.5 \%$ when charging was initiated at a DCFC. With a Leaf battery of $24 \mathrm{kWh}$, this load profile would require approximately 15 minutes to deliver the $10.7 \mathrm{kWh}$ energy to reach an $80 \%$ state of charge at the maximum power levels.

While the duration of the connect event was available in the data source for the first 8 months of 2013, the duration of the energy delivery event was not; therefore, some PEVs may have terminated their charge sometime prior to being disconnected.

The San Diego-specific DCFC data for the first and fourth quarters of 2013 were reviewed for any idle time between the completion of a power event and its subsequent disconnect. No idle times were found. The distribution of connect times for San Diego in the fourth quarter of 2013 was also investigated. Figure 10 shows this distribution, which closely matches the distribution of all DCFC for the first 8 months of 2013 (Figure 6).

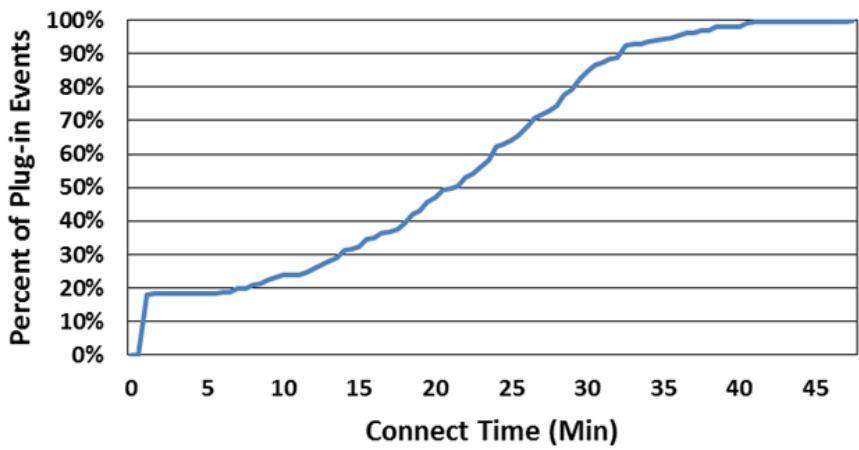

Figure 10. Cumulative distribution of plug-in events for San Diego during the fourth quarter of 2013.

Thus, the charge data of Figure 10 with longer than 30-minute duration are likely due to the Leaf's BMS restricting the energy consumed, rather than PEVs connected past the time of charge completion. Figure A-2 provides a scatter diagram of each charge event, showing the charge duration and energy consumed. Dividing the energy consumed by time provides an average power acceptance per charge. Figure A-2 shows the Leaf's BMS energy restriction as a common occurrence because the average power acceptance by the Leaf for the first 8 months of 2013 was approximately $24 \mathrm{~kW}$.

\section{Observations}

The introduction of usage fees had a negative effect on the utilization of DCFCs, because the average utilization declined from 281.6 charge events per DCFC in the second quarter of 2013 to 100.1 charge events per DCFC in the fourth quarter of 2013. The quarterly reports show that the total number of charging events dropped from 26,911 in the second quarter to 11,704 in the fourth quarter (i.e., a $56 \%$ reduction).

While utilization of DCFCs in terms of connect events declined, the overall shape of connectivity remained the same. Because the charge commenced immediately upon connectivity to the DCFC, both the peak of approximately $11 \%$ in connectivity of available DCFCs and median demand of approximately $0.20 \mathrm{MW}$ occurs between 4 and 7 p.m. daily.

The San Francisco region contained the largest number of DCFCs in The EV Project and their utilization contributes most significantly to the overall energy and demand seen globally in EV Project data. 
Half of all connect events were 20 minutes or less in duration. An average of $8.2 \mathrm{kWh}$ of energy was consumed during these events, with $80 \%$ of all events being less than 30 minutes.

While the maximum power accepted by the Leaf was $50 \mathrm{~kW}$, the average Leaf's BMS acceptance was approximately $24 \mathrm{~kW}$.

With the Leaf's average battery $35.5 \%$ state of charge when charging was initiated at a DCFC, approximately 15 minutes would be required to deliver the $10.7 \mathrm{kWh}$ energy needed to reach $80 \%$ state of charge at the maximum DCFC power level.

\section{About The EV Project}

The EV Project was the largest PEV infrastructure demonstration project in the world, equally funded by the United States Department of Energy (DOE) through the American Recovery and Reinvestment Act and private sector partners. The EV Project deployed over 12,000 AC Level 2 charging stations for residential and commercial use and 100 dual-port DCFCs in 17 U.S. regions.

Approximately 8,300 Nissan LEAFs ${ }^{\mathrm{TM}}$, Chevrolet Volts, and Smart ForTwo Electric Drive vehicles were enrolled in the project.

Project participants gave written consent for EV Project researchers to collect and analyze data from their vehicles and/or charging units. Data collected from the vehicles and charging infrastructure represented almost 125 million miles of driving and 4 million charging events. The data collection phase of The EV Project ran from January 1, 2011, through December 31, 2013. Idaho National Laboratory is responsible for analyzing the data and publishing summary reports, technical papers, and lessons learned on vehicle and charging unit use.

\section{Company Profile}

Idaho National Laboratory is one of DOE's

10 multi-program national laboratories. The laboratory performs work in each of DOE's strategic goal areas: energy, national security, science, and the environment. Idaho National Laboratory is the nation's leading center for nuclear energy research and development. Day-to-day management and operation of the laboratory is the responsibility of Battelle Energy Alliance.

For more information, visit avt.inl.gov/evproject.shtml and avt.inl.gov/chargepoint.shtml.

\section{References}

${ }^{1}$ What Are the Early Experiences in Using Direct Current Fast Chargers?, http://avt.inl.gov/pdf/EVProj/12644730174.dcfc-initexp.pdf.

${ }^{2}$ What Is the Impact of Utility Demand Charges on a Direct Current Fast Charger Host?, avt.inl.gov/evproject.shtml.

${ }^{3}$ What Were the Cost Drivers for the Direct Current Fast Charging Installations?,

http://avt.inl.gov/pdf/EVProj/WhatWereTheCostDriversForD CFCinstallations.pdf.

${ }^{4}$ What Were the Use Patterns Observed at the HighlyUtilized Direct Current Fast Charge Sites?, avt.inl.gov/evproject.shtml.

${ }^{5}$ Potential Consumer Response to Electricity Demand Response Mechanisms: Early Plug-in Electric Vehicle Drivers in San Diego, California, UC Davis Institute of Transportation Studies, UCD-ITS-RR-13-12. 


\section{EVProject}

\section{Appendix A \\ DCFC Graphs}

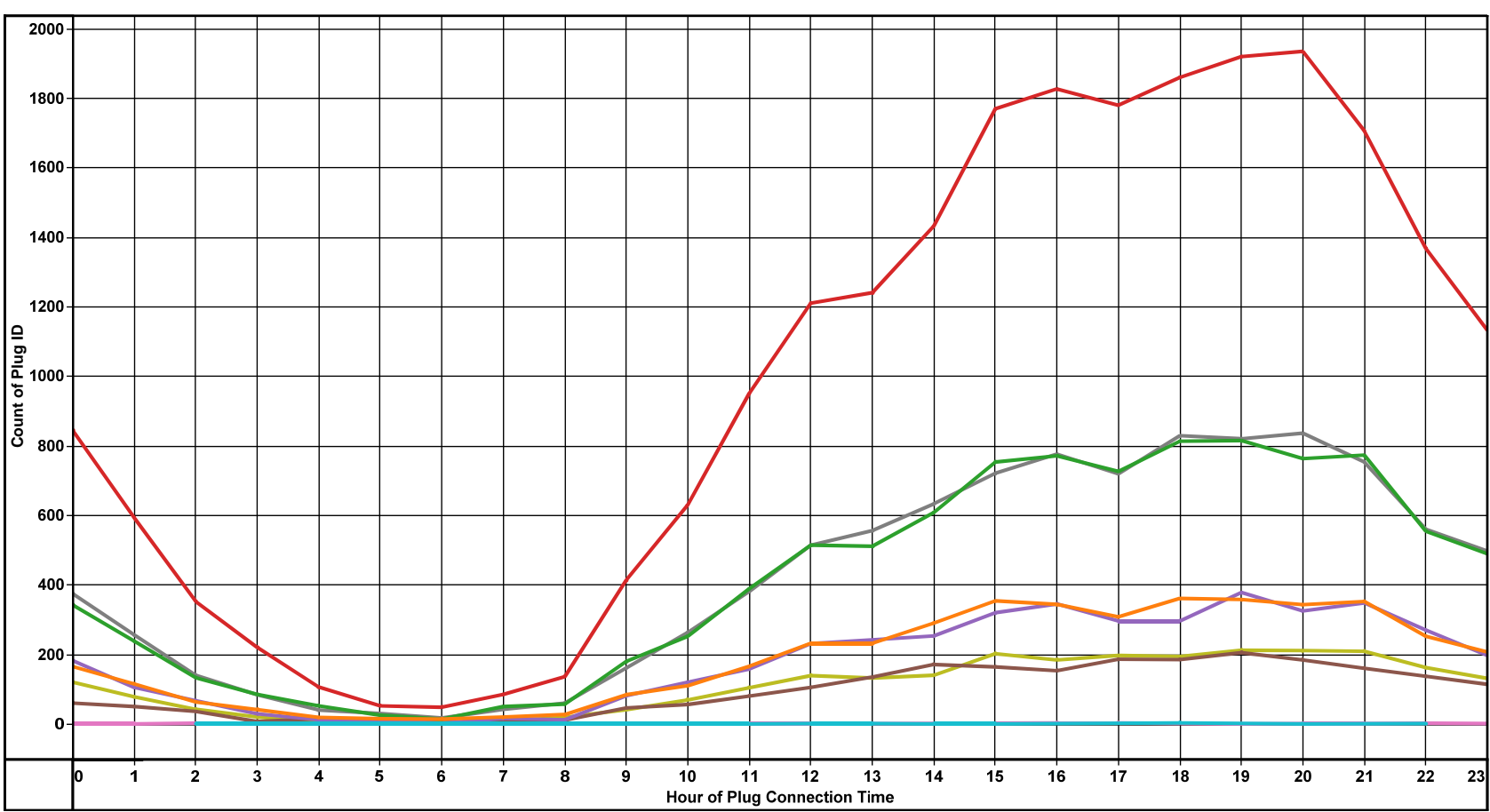

Figure A-1. DCFC plug-in events by time of day by EV Project region.

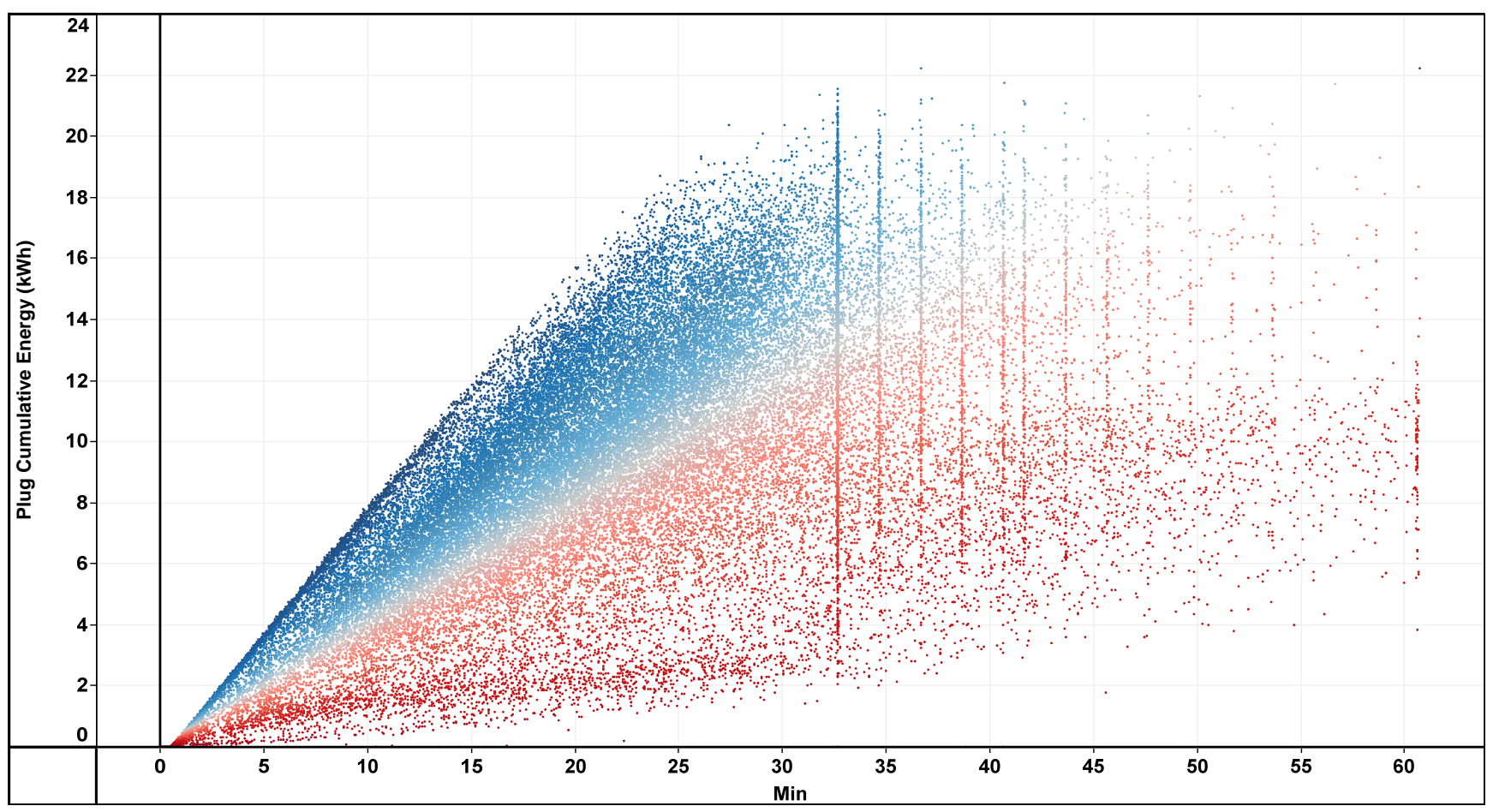

Figure A-2. Plug-in cumulative energy consumed versus time connected. 
The maximum (i.e., blue) slope shows the typical average power acceptance of approximately $48 \mathrm{~kW}$. The white area between the red and blue area occurs at an average power acceptance of approximately $24 \mathrm{~kW}$. The reason for the apparent vertical bars at 2-minute intervals at $32.68,34.68,36.68,38.68,40.68$, and so forth minutes was not investigated. 